\title{
Comparison of Computational Approaches for Rapid Aerodynamic Assessment of Small UAVs
}

\author{
Theresa C. Shafer, $\mathrm{PhD}^{1}$, C. Eric Lynch, $\mathrm{PhD}^{2}$ \\ NAVAIR, Patuxent River, MD 20670 \\ Sally A. Viken ${ }^{3}$ \\ NASA Langley Research Center, Hampton, VA 23681-2199 \\ Noah Favaregh ${ }^{4}$ \\ Analytical Mechanics Associates, Hampton, VA, 23666 \\ Cale Zeune ${ }^{5}$ \\ Wright Patterson Air Force Base, Wright-Patterson, OH 45433 \\ Nathan Williams, $\mathrm{PhD}^{6}$ \\ Defence Technology Agency, Auckland, New Zealand \\ and \\ Jonathan Dansie ${ }^{7}$ \\ Defence Science and Technology Organisation, Melbourne, Australia
}

Computational Fluid Dynamic (CFD) methods were used to determine the basic aerodynamic, performance, and stability and control characteristics of the unmanned air vehicle (UAV), Kahu. Accurate and timely prediction of the aerodynamic characteristics of small UAVs is an essential part of military system acquisition and air-worthiness evaluations. The forces and moments of the UAV were predicted using a variety of analytical methods for a range of configurations and conditions. The methods included Navier Stokes (N-S) flow solvers (USM3D, Kestrel and Cobalt) that take days to set up and hours to converge on a single solution; potential flow methods (PMARC, LSAERO, and XFLR5) that take hours to set up and minutes to compute; empirical methods (Datcom) that involve table lookups and produce a solution quickly; and handbook calculations. A preliminary aerodynamic database can be developed very efficiently by using a combination of computational tools. The database can be generated with low-order and empirical methods in linear regions, then replacing or adjusting the data as predictions from higher order methods are obtained. A comparison of results from all the data sources as well as experimental data obtained from a wind-tunnel test will be shown and the methods will be evaluated on their utility during each portion of the flight envelope.

\footnotetext{
${ }^{1}$ Aerospace Engineer, Applied Aerodynamics and Store Separation Branch, 48110 Shaw Road, AIAA Member

${ }^{2}$ Aerospace Engineer, Applied Aerodynamics and Store Separation Branch, 48110 Shaw Road, AIAA Member

3 Assistant Branch Head for Configuration Aerodynamics Branch, 16 Victory Street, AIAA Senior Member

4 Supervising Engineer, AeroSciences, 21 Enterprise Parkway, Suite 300, Hampton, VA 23666, AIAA Member (deceased)

5 Aerospace Engineer, AFRL Air Vehicles Directorate, 2130 8th St, AIAA Member

6 Research Scientist, Defence Technology Agency, Naval Base, Devonport Auckland

${ }^{7}$ Aerospace Engineer, DSTO Aerospace, 506 Lorimer Street, Fishermans Bend
} 


\section{Nomenclature}

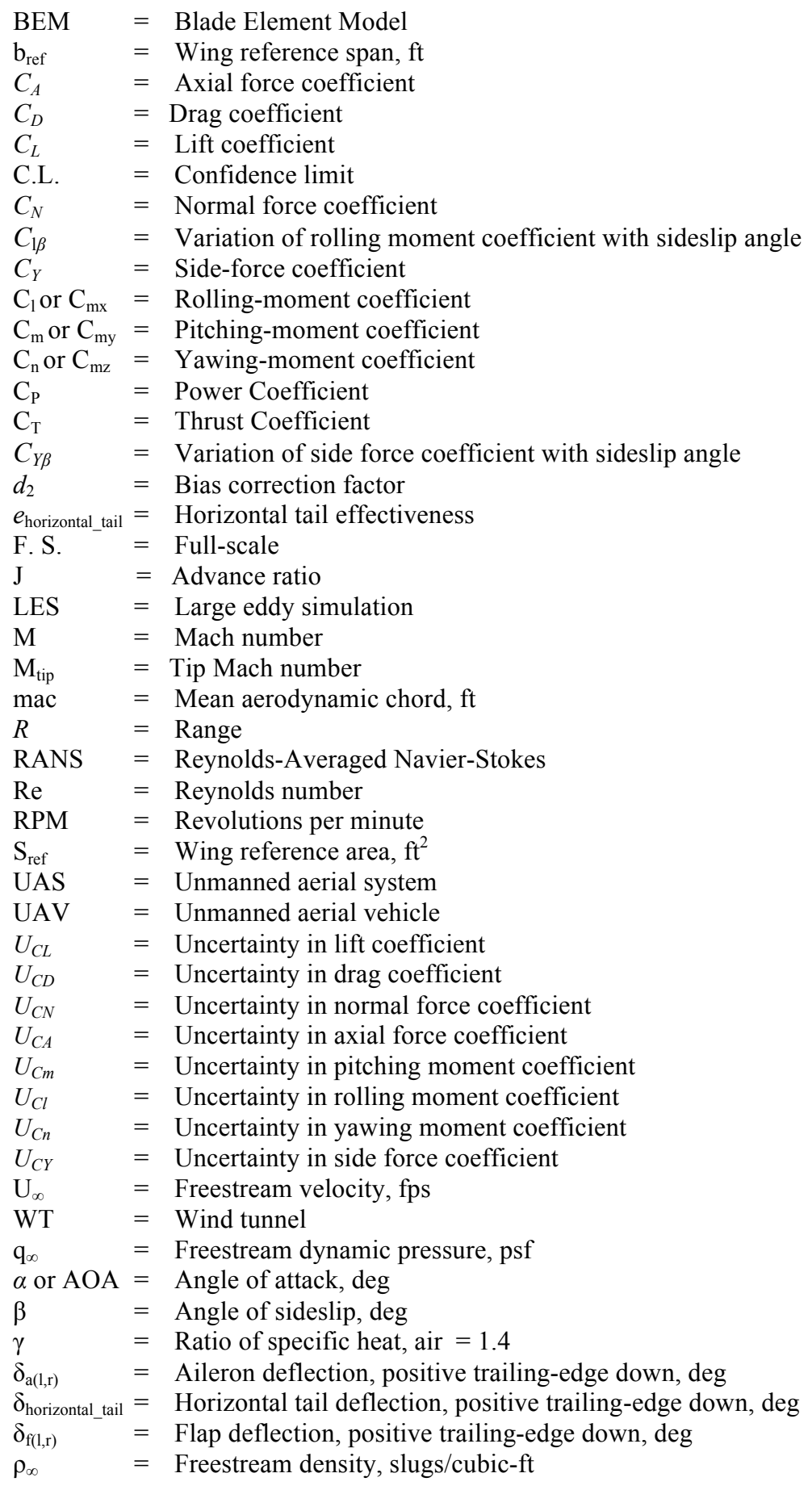

\section{Introduction}

Tnmanned Aerial Vehicles (UAV) support a wide variety of missions around the world. They are an integral part of military defense networks, and provide monitoring capabilities for border control and environmental research, as well as support humanitarian efforts. UAVs are potentially cheaper to acquire and operate than equivalent manned aircraft and can reduce the risk of harm to our warfighters and pilots while accomplishing many of the same missions. Before UAVs are approved to fly, they are required to obtain flight clearance authorization, which ensures the vehicle can operate safely within its limits. Many small UAVs, loosely described as less than $30 \mathrm{ft}$ 
in span and $500 \mathrm{lbs}$, do not have comprehensive aerodynamic databases, which are required to assess the airworthiness of the vehicle. The objective of the work presented in this paper was to determine efficient analytical approaches and compare computational tools used to provide information on the level of fidelity required to build aerodynamic databases that could support the flight certification for small UAVs. A small UAV from New Zealand, Kahu, was selected for this work. The vehicle size, availability of geometry and the ability to share vehicle information made this platform a suitable choice for this evaluation.

A few of the challenges facing this task relate to the low flight speed of the vehicle, low Reynolds number (Re) computational analysis including laminar to turbulent flow prediction and transition, rapid turnaround times versus fidelity requirements and power effects. To determine the aerodynamic forces and moments acting on a small UAV, lower-order (potential flow codes) and higher-order (Navier-Stokes codes) methods were considered. While the aerodynamic characteristics for the entire flight regime of the UAV could be predicted with Navier-Stokes (N-S) codes, the results of a panel code could compliment the results of the Navier-Stokes analysis by increasing the amount of data that could be generated, enabling a more thorough examination of the flying qualities of the vehicle. For example, at a minimum, flying qualities engineers need the forces and moments acting on the vehicle at the maximum and minimum control surface deflections; however, they would prefer to know the forces and moments at many deflection angles. Each aileron, flap, horizontal tail and rudder deflection requires the generation of individual CFD grids for the N-S codes, but when time is constrained this is not possible. Supplemental data from lower-order analytical methods could provide the flying qualities engineers with force and moment data at many deflection angles. This paper provides comparisons between lower-order methods and high fidelity analysis.

If the aerodynamic forces and moments acting on small UAVs are to be predicted accurately then the power effects should be considered. On small UAVs, the engines and propellers are generally located in close proximity to the wing causing large changes to the airflow around the aircraft. To model the power effects on small UAVs, the engine and propeller characteristics (thrust, torque, engine RPM's) must be known. However, these characteristics are often not available to the CFD engineer. Especially important is understanding propeller wake effects on control surfaces (ailerons, elevator, rudder), and the impact on airplane stability, control and handling qualities. The Australian Defence Science and Technology Organisation (DSTO) performed a test of the Kahu's propulsion system. The data was used to validate computational power-on analysis.

Another limitation to small UAV computational analysis is the lack of accurate, comprehensive data for validation. With the resources that were available for the current effort, a full-scale UAV wind tunnel model was constructed by NASA Langley Research Center (LaRC) and tested in their 12-Foot Low Speed facility. A full-scale model was constructed of Kahu UAV, a small $7.5 \mathrm{lb}$ vehicle, developed by the New Zealand Defence Technology Agency (NZ-DTA). The wind tunnel speed was comparable to actual flight speeds. This wind tunnel is primarily used for stability and control testing, however, the force and moment data from the test are presented to compare and contrast against the different CFD results. A more ideal option would be to create a wind tunnel test aerodynamic database of the small UAV in a larger closed circuit full scale facility to obtain higher fidelity low Reynolds number, low dynamic pressure data.

This work was conducted under the auspices of The Technical Cooperation Program (TTCP) AER/WPN TP-5 Aircraft and Weapons Flight Sciences Panel. Members from the United States, United Kingdom, Canada, Australia and New Zealand contributed to this effort. TTCP is an international organization that collaborates in defense scientific and technical information exchange, program harmonization and alignment, and shared research activities. A benefit to working collaboratively on this effort was to combine a broad set of resources to contribute to the process for CFD aerodynamic database generation of small UAVs. The Kahu UAV was provided by the NZ-DTA for this project through the TTCP arrangement.

\section{Kahu UAV}

The Kahu UAV is shown in Figure 1. It is a medium aspect ratio wing, small UAV with two sets of control surfaces. Pitch is controlled using the moving horizontal tail $\left(-12^{\circ}<\delta_{\text {horizontal } \_ \text {tail }}<10^{\circ}\right)$. Roll is controlled by the ailerons $\left(-16^{\circ}<\delta_{\mathrm{a}}<18^{\circ}\right)$, which also double as flaps. The flaps and ailerons are together called flaperons. The flaps have a maximum deflection angle of $9^{\circ}$. There is no rudder control. The vehicle geometric characteristics can be found in Table 1. 


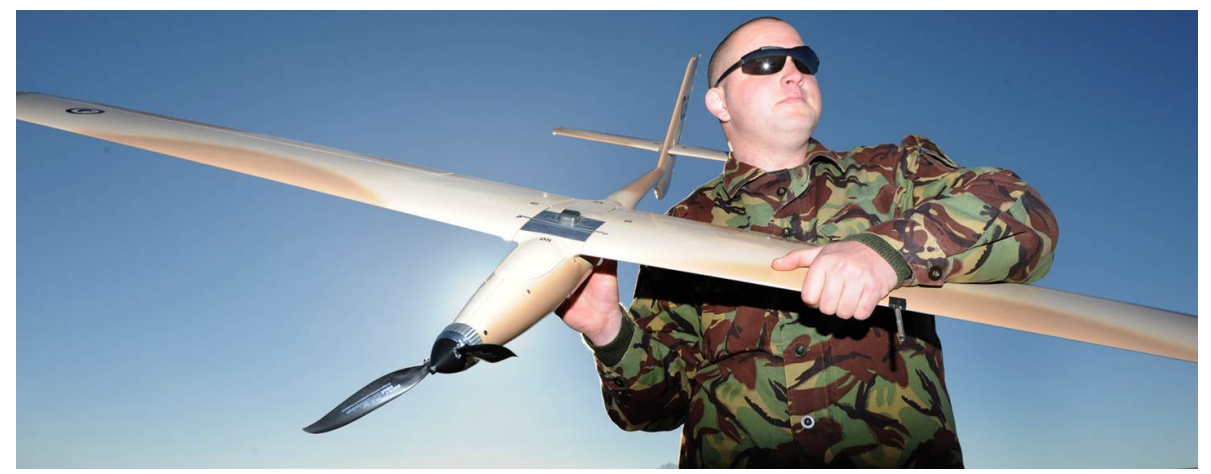

Figure 1 Kahu Unmanned Air Vehicle

Table 1. Kahu Vehicle Characteristics

\begin{tabular}{|l|c|}
\hline $\mathrm{S}_{\text {ref }}\left(\mathrm{ft}^{2}\right)$ & 5.106 \\
\hline $\mathrm{b}_{\text {ref }}(\mathrm{ft})$ & 7.5 \\
\hline mac $(\mathrm{ft})$ & 0.69 \\
\hline Length $(\mathrm{ft})$ & 3.74 \\
\hline MTOW (lb) & 8.6 \\
\hline Cruise (KTAS) & 30 \\
\hline
\end{tabular}

\section{Computational Methods Used}

\section{A. Navier-Stokes RANS and RANS/LES Methods}

The three high-fidelity Navier-Stokes computational tools used for this study were Kestrel, Cobalt and USM3D.

Kestrel $^{1,2}$ is a product of the CREATE-AV Program that is an element of the Computational Research and Engineering for Acquisition Tools and Environments (CREATE) Program sponsored by the U.S. Department of Defense HPC Modernization Program Office. Kestrel is a second-order, cell-centered, finite-volume Navier-Stokes flow solver that is capable of analyzing grids with arbitrary cell topologies. Kestrel can be used to generate steadystate or time-accurate solutions. Kestrel is capable of using several different flux schemes, limiters and turbulence models. Moving control surfaces, aeroelastic analysis, overset grids and rigid-body motions are some of the features in V3.0 of Kestrel. The overset capability of Kestrel was used to analyze power-effects of Kahu.

Cobalt ${ }^{3}$ is a product of Cobalt Solutions LLC. Cobalt is a parallel, compressible Euler/Navier-Stokes flow solver applicable to geometries of arbitrary complexity. Its principal design features are stability, accuracy, and ease-ofuse. Two- and three-dimensional unstructured grids of arbitrary cell topology are supported along with overset grids, rigid-body motion, three equations of state, eight turbulence models, and over 20 boundary condition types. Cobalt provides detailed flow field diagnostics and direct output to major commercial post-processors.

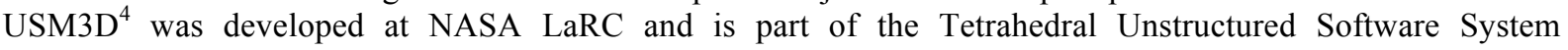
(TetrUSS). The code is a parallelized three-dimensional, cell-centered, finite-volume Euler/Navier-Stokes flow solver for unstructured, tetrahedral meshes. Inviscid flux quantities are computed across each tetrahedral cell face using various upwind schemes. The MinMod and Superbee flux limiter are also implemented within USM3D. Spatial discretization is accomplished by a novel reconstruction process, based on an analytical formulation for computing solution gradients within tetrahedral cells. The solution can be advanced in time by a second-order "physical" time step scheme, a second-order "dual" time step scheme, or to steady-state using local time stepping. Several turbulence models are available: the one-equation Spalart-Allmaras (SA) model, and several two-equation models by Jones and Launder $k$-epsilon model, Menter shear stress transport (SST) model, two nonlinear algebraic Reynolds stress models (ARSM) of Girimaji and Shih/Zhu/Lumley (SZL), and the Wilcox $1988 k$-omega model. Detached eddy simulation (DES) has been implemented in all of the turbulence models. USM3D is second-order in space and time.

The one-equation Spalart-Allmaras ${ }^{5}$ (SA) turbulence model $^{4}$ was used with USM3D. The majority of the N-S analysis was performed fully turbulent with the SA turbulence model. A select few cases were run laminar. The Spalart-Allmaras turbulence model can be combined with LES formations outside of the boundary layer to form the SA-DDES (Delayed Detached Eddy Simulation) flow solver. The SA-DDES approach was tested with Cobalt and Kestrel. 


\section{B. Potential Flow Methods}

The potential flow methods used for this study were PMARC ${ }^{6}$, LSAero and XFLR5 ${ }^{7}$. Low order potential flow methods have the advantage of shorter computation time but require extra models to account for viscous effects.

Panel Method Ames Research Center (PMARC) is a low order, three-dimensional, potential flow panel code. Low-order panel method incorporates constant-strength singularities over each panel such that the velocity potentials satisfy Laplace's equation. PMARC includes features such as internal flow modeling, jet plume modeling, and a time-stepping wake model that allows the study of both steady and unsteady motions. PMARC has extensive geometry modeling capabilities for handling complex, three-dimensional surfaces. It supports quad elements and requires the specification of a wake geometry.

Lifting Surface AEROdynamics (LSAero) and XFLR5 were used together. LSAero is low fidelity aerodynamic estimation tool developed by DSTO and is a panel code implementation of the Vortex Lattice Method ${ }^{8}$. The inviscid drag polar generated by LSAero was supplemented with an estimate of $C_{\text {Do }}$ generated by XFLR5. XFLR5 is a freely available tool for low Reynolds number analysis. It has a number of inviscid panel method solvers, and contains the viscous boundary layer model used in XFOIL ${ }^{9}$. The analysis using LSAero and XFLR5 did not include the fuselage, only the wing and tail surfaces were modeled.

\section{Empirical Methods}

The empirical methods used for this study were the USAF Digital Datcom ${ }^{10}$ and classical hand-book type methods. The USAF Stability and Control Datcom calculates static stability, high-lift and control device, and dynamic-derivative characteristics based on empirical data. The drag predictions are not recommended for performance applications. The hand-book type methods are based on basic aerodynamic theory and empirical data.

\section{Wind Tunnel Test and Setup}

\section{A. NASA Wind Tunnel Facility}

The Kahu wind tunnel test was conducted in the NASA LaRC 12-Foot Low Speed facility, which is a closedcircuit atmospheric tunnel of octagonal cross section, within a 60 -foot diameter sphere enclosure ${ }^{11}$. This facility is a low fidelity tunnel for exploratory testing that has been used predominantly for stability and control testing rather than performance testing. The test section airflow is produced by a 15.8 foot-diameter, 6 -blade drive fan in which the tunnel can reach speeds up to $70 \mathrm{ft} / \mathrm{sec}$ (dynamic pressure up to $6 \mathrm{psf}$ ). In addition, the facility can accommodate an angle-of-attack range up to $90^{\circ}$ and full angle of sideslip range $\left( \pm 90^{\circ}\right)$ in a single model mounting arrangement (mounting models inverted allows for similarly large negative angles of attack). The tunnel is capable of static and dynamic (forced oscillation and free-to-roll) testing to acquire force and moment data using a 6component internal strain-gage balance. Digital video cameras are available for recording views of the model and test section while tunnel is in operation.

\section{B. Kahu Wind Tunnel Model Description}

The full-scale Kahu wind tunnel model was designed and built at NASA LaRC to match the outer mold line of the actual production full-scale flight vehicle with movable control surfaces (flaperons [flaps/ailerons] and an all moving horizontal tail). The model was primarily constructed of polycarbonate core with composite skins. The fuselage mid-section for the bulkhead region, balance block mount, and wing carry through was aluminum. The front and aft parts of the fuselage were constructed of polycarbonate material with an aluminum tube through the inside of the aft end for structural integrity and room for a push rod for horizontal tail rotation. The horizontal tail was constructed of foam core with composite skin to make it lightweight. Model modifications to the underside of fuselage were done to accommodate attachment to the balance/support system. The model is shown in Figure 2. The balance moment reference center for the wind tunnel model was located near the flight vehicle center of gravity (c.g.) location in $\mathrm{x}$ - and y-axis but offset slightly in z-axis due to the requirement to fit the balance within model. During testing, the tunnel force and moment data was translated to correspond to the flight vehicle reference c.g. location. A loads test (safety factor of 1.5 for $\mathrm{q}_{\infty}=4 \mathrm{psf}$ ) and a quality assurance (QA) check followed the model construction to verify that it met safety load limits and configuration dimensions. During the QA scan of the model, it was noted that the wing had a slightly less dihedral compared to the CAD model, with the starboard side having 0.391 " less deflection at the wing tip and the port side having 0.189" less deflection at the wing tip. During the loads test, the starboard wing tip deflection was measured as $1.448^{\prime}$ " and the port wing tip deflection was measured as 1.394 " as compared with the unloaded model, resulting in less than $2^{\circ}$ deflection at the tip. In addition, an electromagnetic interference (EMI) check was conducted to verify no issues. 

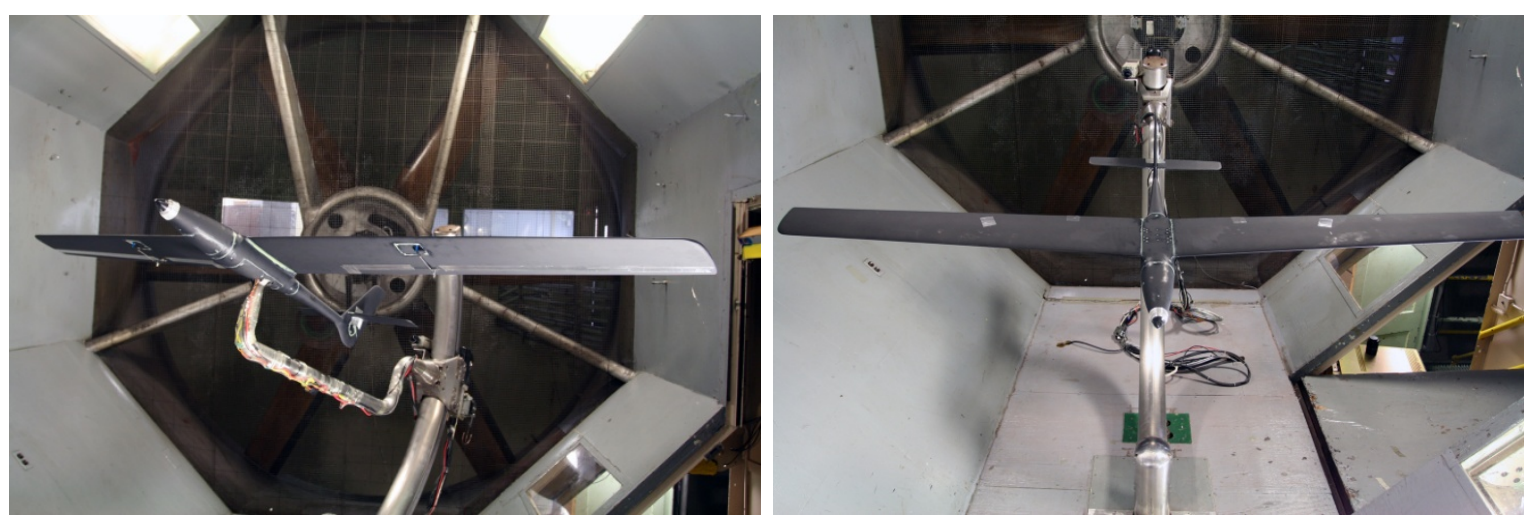

Figure 2 Kahu Wind Tunnel Model Installed in the NASA Langley's 12ft Low Speed Facility

\section{Kahu Model Instrumentation}

A functional design of the wind tunnel model was conducted thus allowing for the implementation of actuators and software so that the control surfaces (flaperons and horizontal tail) and propeller could be integrated with the tunnel software system and controlled from the tunnel control room using a defined schedule for each run. In addition to angle measuring sensors and the aforementioned 6-component balance, the wind tunnel model was instrumented with flight hardware including a propeller, electric motor (operated at 0-6000 RPM), motor controller, digital wing and horizontal tail servos, and a serial servo controller. For long duration operations in the facility, a battery eliminator circuit and an externally housed 24-volt high-capacity power supply provided electrical power to the servo controller, servo motors, and propeller. Due to the small size of model, no control surface position sensors were used; calibrated commands served as the sole source of the control surface knowledge during the wind-on test runs.

The balance (FF09D) design loads and calibration accuracies are shown in Table 2. The calibration accuracies expressed as aerodynamic coefficients based on the test conditions are shown in Table 3.

Table 2. NASA LaRC FF09D balance design loads and calibration accuracies.

\begin{tabular}{|l|c|c|c|}
\hline \multicolumn{4}{|c|}{ FF09D Balance } \\
\hline Component & $\begin{array}{c}\text { Design Load } \\
\text { (lbs or in-lbs) }\end{array}$ & $\begin{array}{c}\text { Accuracy } \\
\text { \% F.S. } \\
(\mathbf{9 5 \%} \text { C.L. })\end{array}$ & $\begin{array}{c}\text { Accuracy } \\
\text { (lbs or in-lbs) } \\
\text { (95\% C.L.) }\end{array}$ \\
\hline Normal Force & \pm 100 & 0.04 & 0.04 \\
\hline Axial Force & 50 & 0.05 & 0.025 \\
\hline Pitching Moment & \pm 480 & 0.04 & 0.192 \\
\hline Rolling Moment & \pm 176.8 & 0.11 & 0.19448 \\
\hline Yawing Moment & \pm 540 & 0.03 & 0.162 \\
\hline Side Force & \pm 60 & 0.07 & 0.042 \\
\hline
\end{tabular}

Table 3. Balance calibration accuracies expressed in terms of aerodynamic force and moment coefficients.

\begin{tabular}{|l|l|l|l|l|l|l|}
\hline$q_{\infty}, p s f$ & $C_{N}$ & $C_{A}$ & $C_{m}$ & $C_{l}$ & $C_{n}$ & $C_{Y}$ \\
\hline 2.5 & \pm 0.00313 & \pm 0.00196 & \pm 0.00182 & \pm 0.00017 & \pm 0.00014 & \pm 0.00329 \\
\hline
\end{tabular}

\section{NASA Tunnel Installation}

The model was instrumented and mounted on a 'bent' sting geometry and then centered and leveled using an angle measurement system. The model was mounted inverted and upright to perform flow angularity corrections. All control surface deflections were calibrated with servo inputs using calibration templates and the propeller RPM was calibrated with power inputs and strobotach timing light measurements. Data cables were run from the model in the tunnel to the control room data acquisition system to allow a fully automated test to be conducted. The Maestro control center was used with the servo controller to command flaperon and horizontal tail settings and a 
motor controller to command RPM setting. No boundary layer tripping on the model was conducted during the wind tunnel test since it was a full-scale model being tested near flight Reynolds number conditions.

\section{E. NASA Wind Tunnel Test}

The full-scale Kahu static wind tunnel test was conducted in the 12-Foot Low Speed facility during a 1-week entry. The test matrix range was defined as in Table 4. Initial checkouts were conducted for flow angularity corrections and also hysteresis effects, which appear to be minimal. Balance unloaded zeros and weight tares for the configuration were also obtained. Six-component force and moment data was acquired with an internally-mounted strain-gage balance. During the initial checkouts, the tunnel was operated at a dynamic pressure of $3.5 \mathrm{psf}$. However, in order to stay within safety limits of the balance maximum rolling moment when applying full cross flaperon controls, wind tunnel testing was conducted at a maximum dynamic pressure of $2.5 \mathrm{psf}(\sim 80 \%$ of rolling moment balance limit). This corresponds to a freestream velocity of $46 \mathrm{fps}$ and a Reynolds number of $1.94 \times 10^{5}$, based on the mean aerodynamic chord.

Table 4 Wind Tunnel Test Matrix Range

\begin{tabular}{|l|c|c|}
\hline \multicolumn{1}{|c|}{ Parameter } & Min & Max \\
\hline$\alpha$ (degrees) & -8 & 30 \\
\hline$\beta$ (degrees) & -20 & 20 \\
\hline$\delta_{\text {horizontal tail }}($ Trailing edge $=+$ down) $($ degrees) & -12 & 10 \\
\hline$\delta_{\text {flaperons }}$ (Trailing edge $=+$ down) $($ degrees) & -16 & 18 \\
\hline Thrust $(\%$ power setting) & 0 & 100 \\
\hline
\end{tabular}

For all data runs, time averaged data was obtained at each point using a 10 -second dwell time. Traditional angle-of-attack and sideslip sweeps were conducted for the unpowered baseline configuration (no surface control deflections or propeller mounted) and also a select few surface control deflection cases. Typical alpha sweeps were $-8^{\circ}$ to $30^{\circ}$ by $1^{\circ}$ increments, with the sweep being defined with finer resolution near stall: $-8^{\circ}$ to $8^{\circ}$ by $1^{\circ}$ increment, $8.5^{\circ}$ to $17^{\circ}$ by $0.5^{\circ}$ increment, and $18^{\circ}$ to $30^{\circ}$ by $1^{\circ}$ increment. Typical beta sweeps were $-20^{\circ}$ to $-6^{\circ}$ by $2^{\circ}$ increment, $-5^{\circ}$ to $5^{\circ}$ by $1^{\circ}$ increment, and $6^{\circ}$ to $20^{\circ}$ by $2^{\circ}$ increment. The model control surfaces were taped (neutral position, $0^{\circ}$ deflection) for the unpowered baseline configuration testing.

In addition, a fully-automated Design of Experiment (DOE) test matrix design was implemented on the Kahu model (with propeller), that included the following independent variables: $\alpha, \beta, \delta_{\mathrm{f}(\mathrm{l})}, \delta_{\mathrm{f(r)}}, \delta_{\text {horizontal_tail }}$, and RPM. The DOE test matrix included six sub-spaces (low alpha, stall and post-stall for both positive and negative beta) for the baseline configuration with control deflections and power effects conducted at each subspace point. The alpha and beta sweeps from the unpowered baseline runs were used to aid in defining the subspace boundaries/centers. A schedule for each sub-space was provided to the test engineer to implement, followed by a validation run across the test space. It should be noted that CFD was instrumental in planning, set-up and finalization of the DOE test matrix. This paper presents only the unpowered baseline configuration (standard testing procedure) data with a few horizontal tail deflection cases. The static DOE data (with power and control surface effects) will be presented at a later date.

Following the DOE testing, flow visualization runs were conducted and recorded with tufts on the upper surface of the wing and on the vertical tail. Angle of attack sweeps were performed for a select number of runs for the baseline configuration with and without flaperon deflections and power effects. In addition, a smoke visualization run was conducted near stall condition to see how the airflow behaved over the lifting surfaces.

The new fully automated testing capability opens the door to future DOE testing in the 12-Foot Low Speed wind tunnel with the capability to use models with control surfaces and propellers. This is a significant capability for investigating Learn-to-Fly techniques for automated simulation model development for performance and flight dynamics analysis.

\section{F. DSTO Kahu Propulsion System Test}

The Kahu propulsion system performance testing was carried out by DSTO ${ }^{12}$. The test setup is shown in Figure 3. Testing was carried out in the DSTO Research Wind Tunnel. Power settings of $30 \%, 50 \%, 70 \%, 90 \%$ and $100 \%$ were tested for airspeeds of $0,6.5,16.4,32.8,49.2,65.6,75.5$ and $88.6 \mathrm{ft} / \mathrm{s}$ and motor supply voltages of $13 \mathrm{~V}$, $14.5 \mathrm{~V}, 16 \mathrm{~V}$ and $17 \mathrm{~V}$. A polynomial regression of thrust and power versus advance ratio and tip Mach number was obtained from the test and used for comparison with computational analysis. 


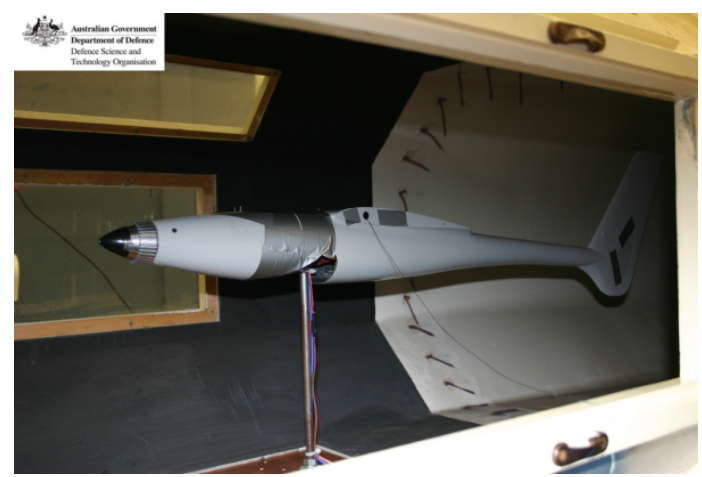

Figure 3 DSTO Kahu Propulsion System Test Setup

\section{Kahu Grid Generation and Run Conditions}

The unstructured grids generated for use with the Navier Stokes (N-S) flow solvers were created using the Tetrahedral Unstructured Software System (TetrUSS). GridTool ${ }^{13}$ and VGRID $^{14-16}$ were used to generate the unstructured tetrahedral grids. The unstructured grids for the aerodynamic analysis were 26-32 million cells and were created with a $\mathrm{y}^{+<1}$ in the boundary layer. Eight separate grids were generated for eight different control surface configurations. The control surface grid matrix is listed in Table 5. Only the baseline and horizontal tail deflection configurations will be discussed in this paper. The Kestrel and Cobalt computational analyses presented here were completed at $\mathrm{Re}=4.0 \times 10^{5}$ and $\mathrm{M}=0.088$ based on the mean aerodynamic chord. A Mach study ranging from values of 0.088 to 0.2 was completed using Kestrel. The USM3D calculations were performed at a $\mathrm{Re}=2.5 \times 10^{5}$, and several runs were also completed at a $\mathrm{Re}=1.94 \times 10^{5}$ to match the wind tunnel test conditions. The wind tunnel test was completed after the computational analysis and the run conditions were constrained by safety limits of the tunnel and set up. Also, since the USM3D flow solver does not have low-Mach number preconditioning, $\mathrm{M}_{\infty}=0.15$ was used for the analyses.

Table 5. Control Surface Grid Matrix

\begin{tabular}{|l|c|c|c|}
\hline & $\begin{array}{c}\text { Horizontal Tail } \\
\text { Deflection, deg }\end{array}$ & $\begin{array}{c}\text { L Flaperon } \\
\text { Deflection, } \\
\text { deg }\end{array}$ & $\begin{array}{c}\text { R Flaperon } \\
\text { Deflection, } \\
\text { deg }\end{array}$ \\
\hline Configuration A & 0 & 0 & 0 \\
\hline Configuration B & -12 & 0 & 0 \\
\hline Configuration C & -5 & 0 & 0 \\
\hline Configuration D & 5 & 0 & 0 \\
\hline Configuration E & 10 & 0 & 0 \\
\hline Configuration F & 0 & 12 & 12 \\
\hline Configuration G & 10 & 18 & 0 \\
\hline Configuration H & 10 & 18 & -16 \\
\hline
\end{tabular}

For the powered analysis several unstructured grids were created using TetrUSS and all grids were analyzed with Kestrel. A mesh of 20 million cells was generated on an isolated propeller. The geometry for the isolated propeller was built by measuring section profiles along the blade. The isolated propeller had a $\operatorname{Re}_{\mathrm{c}}=5 \times 10^{4}$ and as a result, all cases were run laminar. The tip Mach number, $\mathrm{M}_{\text {tip }}$, was fixed at 0.2369 , which corresponds to $50 \%$ power. An advance ratio $\left(\mathrm{J}=\mathrm{U}_{\infty} / n \mathrm{D}\right.$, where $n$ is the propeller speed in revolutions per second and $D$ is the diameter) sweep was conducted for the isolated propeller. The time step was varied from an eighth of a degree of rotation per step to a half-degree rotation. An overset spinning propeller mesh and aircraft mesh were also analyzed. The fuselage was modeled without wings to represent the test article from the DSTO engine test. It had 38 million cells. The overset propeller mesh had 4 million cells. A time step corresponding to $0.5^{\circ}$ of rotation per step was chosen. An advance ratio sweep at $\mathrm{M}_{\text {tip }}=0.2369$ was conducted. For the last set of powered analysis, grids with actuator disks were used. Four grids including fuselage and tail were generated with and without an actuator disk and with the horizontal tail pitched $0^{\circ}$ and $2^{\circ}$. All four grids had 38 million cells each. An example of the surface mesh can be found in Figure 4. 


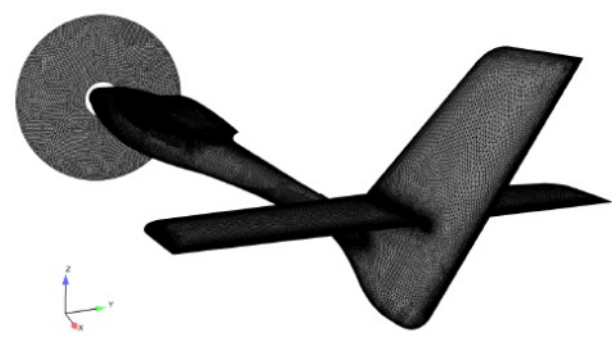

Figure 4 Kahu Surface Mesh with Actuator Disk and without Wings

The structured mesh created for use with PMARC was created using $\mathrm{Gmsh}^{17}$. Gmsh is a three-dimensional finite element mesh generator with built-in pre- and post-processing capabilities. PMARC was used to evaluate Configurations A, C and D in Table 5. LSAero and XFLR5 both have built in meshing codes, and these codes were used to generate meshes with fewer than 1000 panels. The structured mesh can be found in Figure 5.

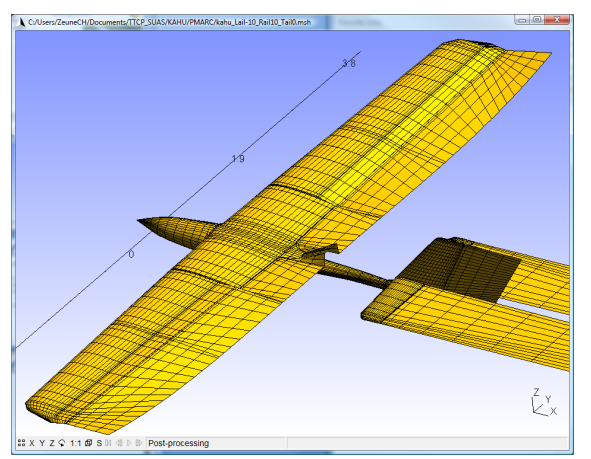

Figure 5 Kahu Structure Mesh for Use with PMARC

\section{Results}

A comparison of all the computational and experimental results is presented in this section. Lift coefficient and drag coefficient data are presented in the stability and control axes, while all other forces and moments are in the body axes. The moments were taken about the vehicle center of gravity. The powered-off computational analysis was run prior to the NASA LaRC wind tunnel test. The bulk of the analysis was run at a Re of $2.5 \times 10^{5}$ based on the mean aerodynamic chord. Also, since the USM3D flow solver does not have low-Mach number preconditioning, $\mathrm{M}_{\infty}$ $=0.15$ was used for the analyses. The wind tunnel test, due to safety limits was conducted at a $\operatorname{Re}$ of $1.94 \times 10^{5}$. A few select points were rerun at the tunnel conditions using Kestrel and USM3D to match the test conditions. Three Re calculations are compared in Figure 6. There was very little difference in lift with varying Re, none in the linear region, for both USM3D and Kestrel. For the fully turbulent results, there was little difference in drag as well (less than 5 counts with varying Re). Based on these results, the wind tunnel test results have been included on the remainder of plots comparing the computational tools that used the higher Re $\left(2.5 \times 10^{5}\right)$. Kestrel was also compared for fully turbulent and fully laminar runs. The laminar runs were only conducted in the linear region. The drag for the laminar analysis at lower angles of attack is closer to the data but there was little difference found at the higher angle of attack. There was very little difference in lift between the laminar and turbulent runs. In the linear region of the curve, the flow over the wing is most likely laminar or transitioning to turbulent flow. Some of the differences observed between the CFD and wind tunnel data are consistent with tunnel interference effects such as: blockage and downwash change. ${ }^{18}$ Barlow, Rae, Jr., and Pope ${ }^{18}$ state that, "A closed jet makes the lift too large and the drag too small at a given geometric angle of attack corresponding to a smaller downwash at the test article than in an unbounded stream." The wind tunnel data have not been corrected for any blockage or wall interference effects. However, the CFD analyses were conducted with the outer boundaries of the computational domain treated with characteristic inflow/outflow boundary conditions. The model has a $7.5 \mathrm{ft}$ span and the tunnel was $12 \mathrm{ft}$ wide. The difference seen with the increased lift-curve slope of the wind tunnel data as compared with the CFD data is consistent with wind tunnel induced effects. The difference in the drag between the N-S solutions and the wind 
tunnel data is larger than expected. Some of the discrepancies here could also be due to testing in the low fidelity tunnel and the challenges associated with testing at such low dynamic pressures. It was also noted during the test that the starboard wing stalled slightly ahead of the port wing thus a milder stall characteristic was observed in the wind tunnel as compared with the CFD. Two repeat alpha sweep runs were assessed to determine the experimental uncertainties for the force and moment coefficients. The range $(R)$ of each aerodynamic coefficient was computed at each point and normalized by $d_{2}\left(d_{2}=1.128\right.$ for $\mathrm{n}=2$ replicates). The maximum value of $R / d_{2}$ for each coefficient was used to estimate the coefficient standard deviations. A margin index of 1.2 was applied to increase the uncertainty to account for errors that are not part of the experimental error (unknown unknowns), (see Table 6). In the future, further CFD analyses are recommended that include modeling the tunnel walls and sting to see if better agreement is achieved between CFD and experimental data. The final wind-tunnel data set (including all the DOE data) will be corrected for known wall interference, blockage and upwash effects.

Table 6. Experimental repeatability uncertainty estimates for force and moment coefficients.

\begin{tabular}{|c|c|c|c|c|c|c|c|c|}
\hline$q_{\infty}, p s f$ & $U_{C L}$ & $U_{C D}$ & $U_{C N}$ & $U_{C A}$ & $U_{C m}$ & $U_{C l}$ & $U_{C n}$ & $U_{C Y}$ \\
\hline 2.5 & 0.04048 & 0.01993 & 0.04509 & 0.00605 & 0.01005 & 0.00326 & 0.00111 & 0.00303 \\
\hline
\end{tabular}
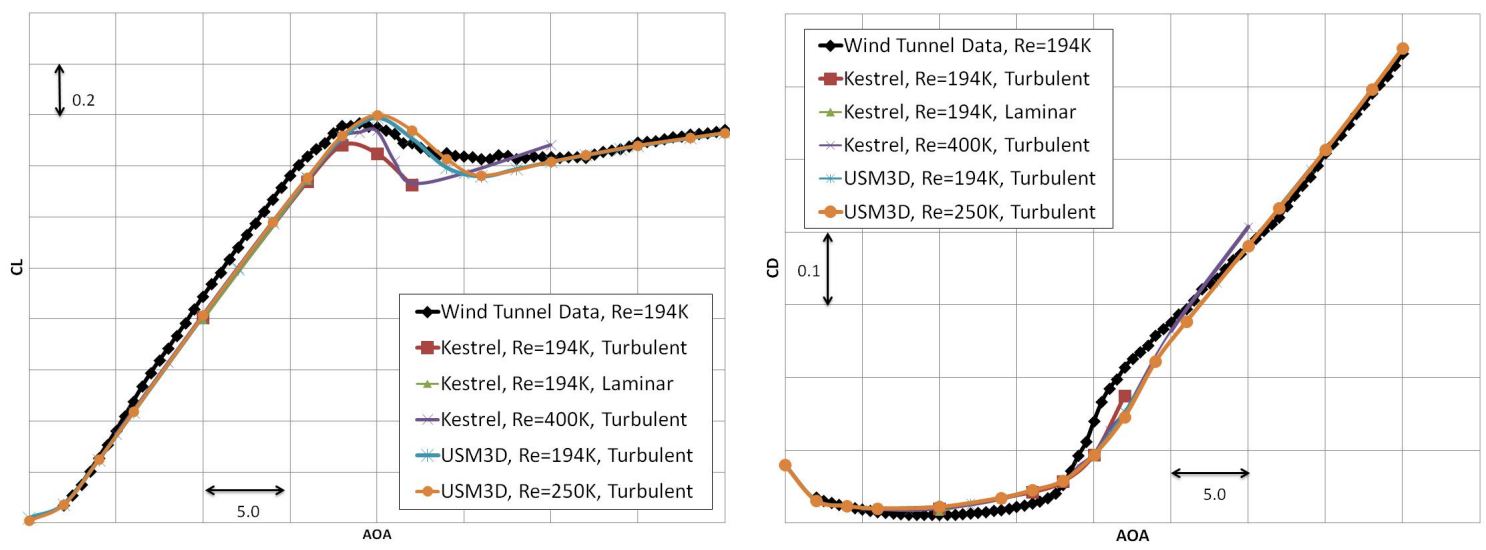

Figure 6. Kahu Lift and Drag Coefficient with Varying of Reynolds Numbers, Power-off.

A drag polar and the lift, drag and pitching moment coefficients as a function of angle of attack can be found in Figure 7 and Figure 8 (with Re of $2.5 \times 10^{5}$ for CFD). The majority of the analysis tools predicted similar lift, drag and pitching moment characteristics up through stall for Kahu. As stated earlier in Section III C, the XFLR5+LSAero analyses did not include the fuselage, only the wing and tail surfaces were modeled. The high fidelity N-S solvers agree very well with each other, however the magnitude of the drag curves differs significantly from the tunnel test for reasons previously discussed. The N-S models are run fully turbulent for these predictions. The stall angle of attack and $\mathrm{C}_{\mathrm{Lmax}}$ were very similar for the N-S solvers. PMARC, XFLR5+LSAero and Datcom do not predict stall but the slope of the linear region was well predicted. XFLR5+LSAero and Datcom predict a similar lift curve to the N-S solvers. Datcom agrees very well with the test data in the linear region. PMARC and the hand book calculations under-predict the magnitude of the linear portion of the lift curve when compared to the other solvers. All codes with the exception of PMARC and Datcom compute similar lift coefficient in the linear region, however N-S solvers are required to accurately predict stall.

In general, the drag and pitching moment coefficients for all analytical tools predict similar trends in the linear region. Datcom and PMARC predicted slightly higher drag than the N-S solvers as the stall region was approached. The N-S solvers and XLR5+LSAero agreed better with the test data for drag coefficient. Pitching moment coefficient computed by the N-S computational tools compares well with the test data. The N-S solvers predicted the dip in pitching moment found in the test.

The N-S solvers required hundreds of processors to run these calculations and took several hours. The potential flow and empirical methods were run on single processor machines and could run in minutes (potential flow) or seconds (empirical). A large aerodynamic database can be produced more efficiently using the low order methods, however, the N-S solvers generally are more accurate for predicting non-linear flow behavior for lift, drag and pitching moment coefficients. 

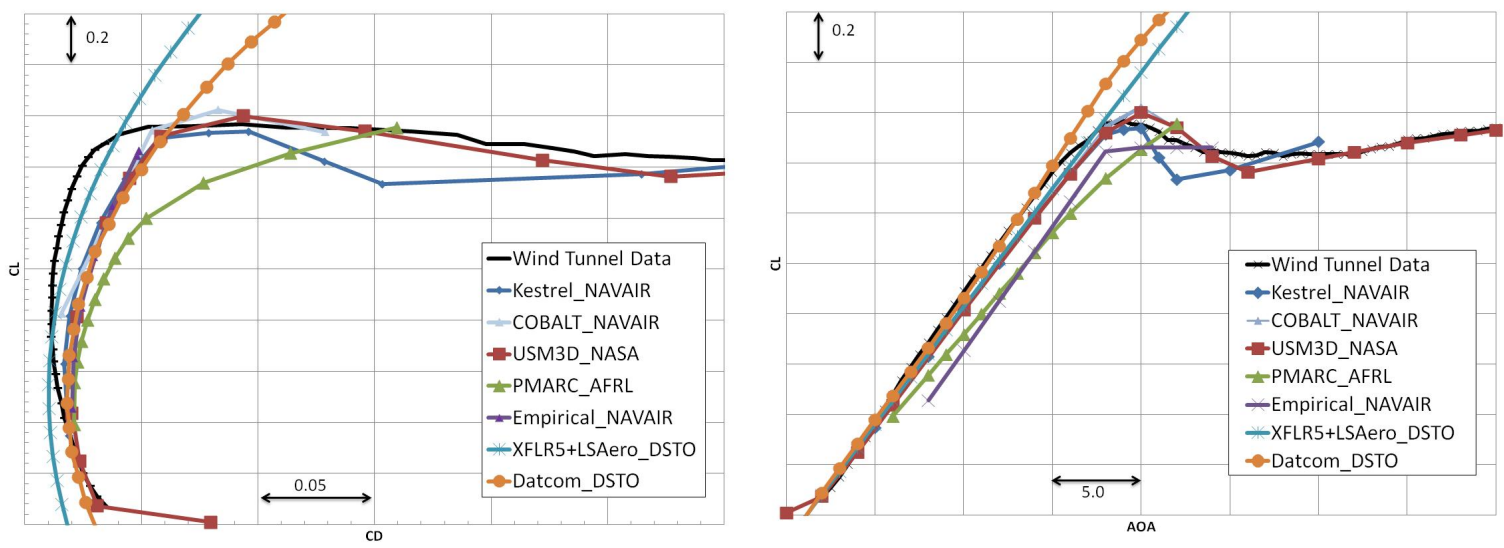

Figure 7. Kahu Drag Polar and Lift Coefficient Comparing Computational Methods, Power-off.
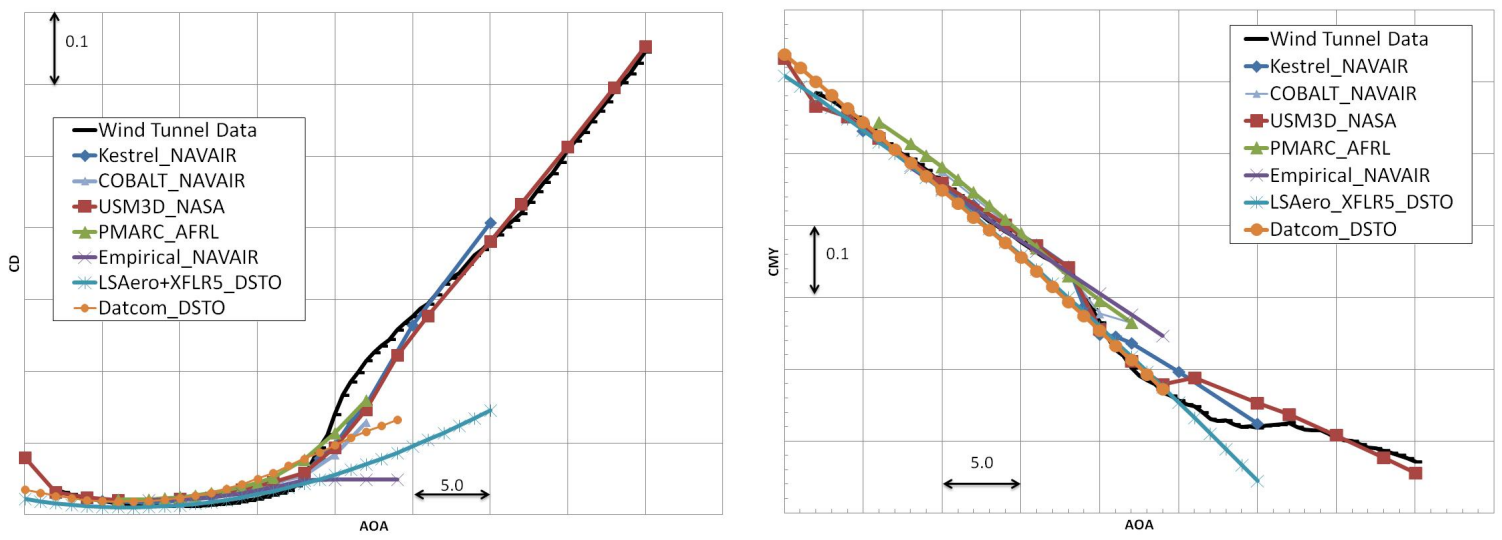

Figure 8. Kahu Drag Coefficient and Pitching Moment Coefficient Comparing Computational Methods, Power-off.

Comparisons were made between USM3D, PMARC, LSAero and the test data for a range of sideslip angles and angles of attack. These comparisons are found in Figure 9 and Figure 10. PMARC and USM3D generally computed lower lift and higher drag than was measured in the wind tunnel data. Both classes of computations seem to predict the increments on CL associated with changing sideslip in the linear region. Again, USM3D was run fully turbulent and a laminar or transition analysis should decrease the drag for low angles of attack. PMARC data was further from the wind tunnel data than USM3D in the linear region and near stall. A change in Beta did not increase or decrease the discrepancy with test data. Yawing moment computed by USM3D and LSAero compared well with the wind tunnel data in the linear region, but PMARC computed a lower value. During the wind tunnel test, the starboard wing stalled slightly ahead of the port wing, leading to an increase in yawing moment as can be seen in Figure 10. The increase in yawing moment found at higher angles of attack due to the difference in wing stall in the wind tunnel data is not shown in the computational analyses. USM3D and LSAero can be used to predict variations in Beta and Alpha for lift, drag and yawing moment coefficients. 

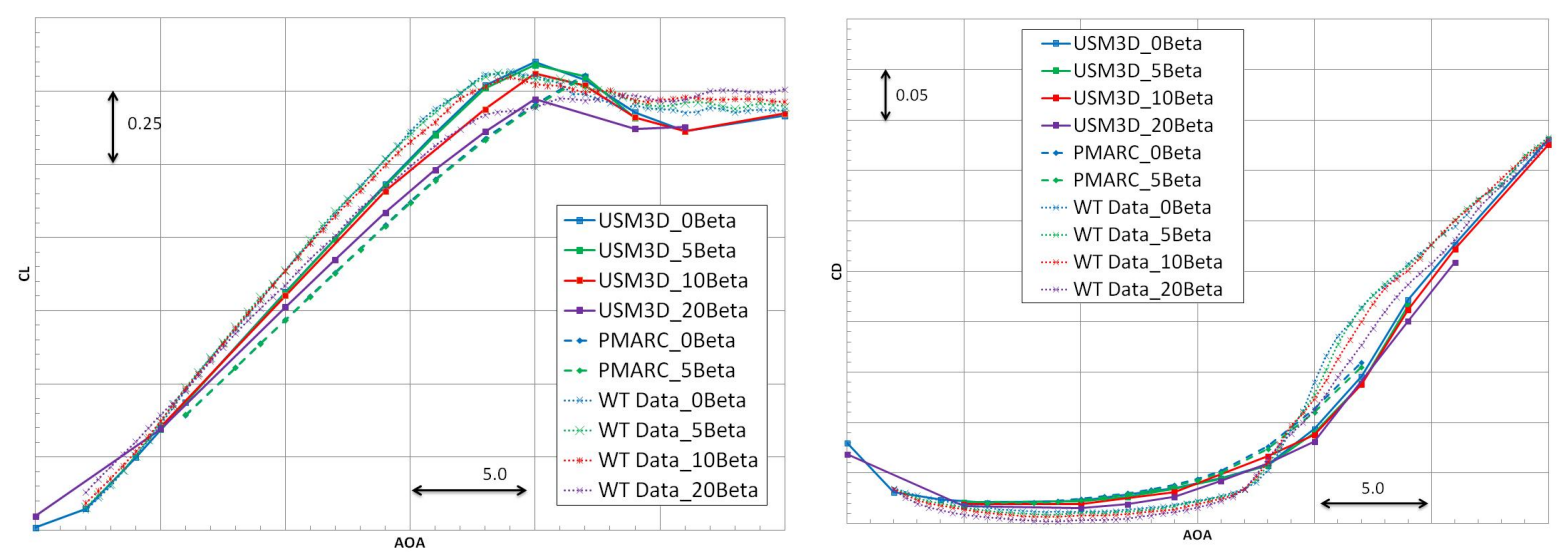

Figure 9 Lift and Drag Coefficient vs AOA for Variations in Sideslip Angle, Power-off.

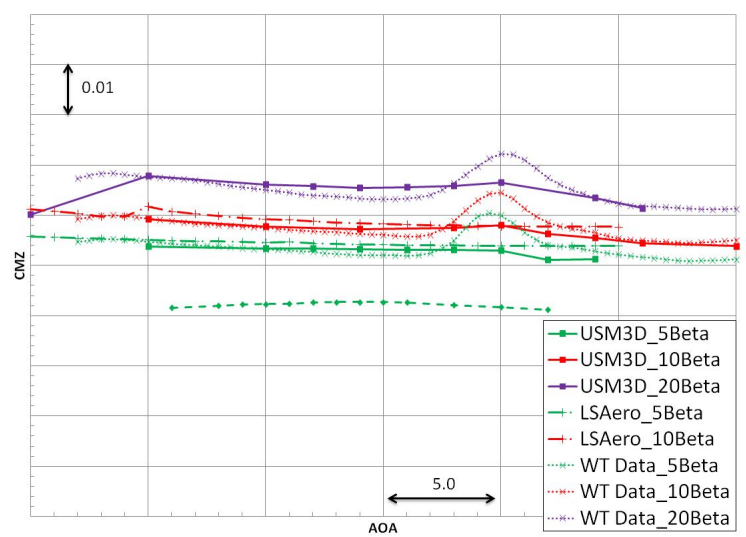

Figure 10 Yawing Moment Coefficient vs AOA for Variations in Sideslip Angle, Power-off.

Figure 11 and Figure 12 compares USM3D, LSAero, Datcom and the test data for rolling moment and side force coefficient versus sideslip angle. The plots demonstrate that Kahu has stable Beta derivatives (y-axis values increase in up direction). $A C_{1 \beta}$ less than 0 is stable and a $C_{Y \beta}$ less than zero is also stable. The rolling moment coefficient at low angles of attack is higher for all computational tools compared to the experimental data. However, USM3D and LSAero predict similar slopes and moderate change with changing angle of attack. Datcom predicts a different slope and a larger difference in rolling moment coefficient with varying angle of attack. For angles of attack of $10^{\circ}$ and $20^{\circ}$, the slope of the rolling moment coefficient curve is much steeper than lower angles of attack due to approaching stall condition or at post-stall condition. USM3D captures the steeper slope at $20^{\circ}$ but not at $10^{\circ}$. This can be explained by the wind tunnel model being at post- $\mathrm{C}_{\mathrm{Lmax}}$ stall condition whereas the CFD data is just at computed $\mathrm{C}_{\mathrm{Lmax}}$. LSAero has a higher slope (less negative) than all other methods and the wind tunnel data at both angles of attack. Datcom has a similar slope as the wind tunnel data at $\alpha=10^{\circ}$ but disagrees in magnitude. Rolling moment coefficient as a function of Beta at various angles of attack is very difficult to predict computationally. The side force coefficient computed by the computational tools for angle of attack of $0^{\circ}$ and $20^{\circ}$ compared fairly well with the wind tunnel data. 


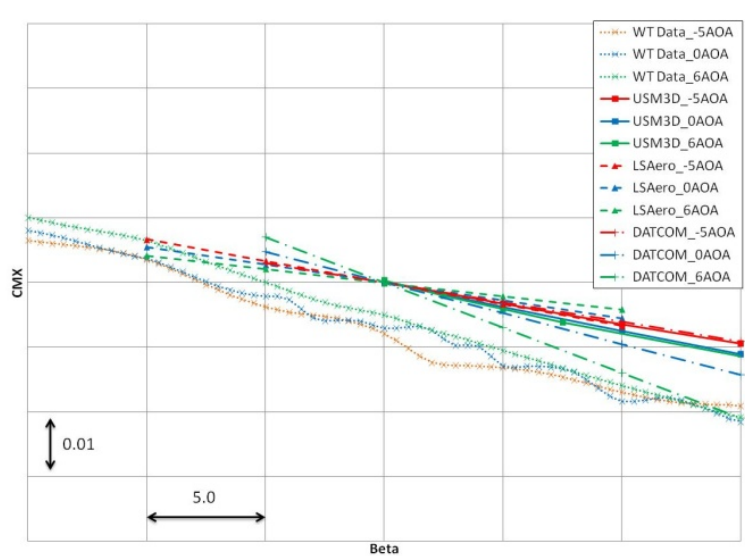

(a) $\mathrm{AOA}=-5^{\circ}, 0^{\circ}, \& 6^{\circ}$

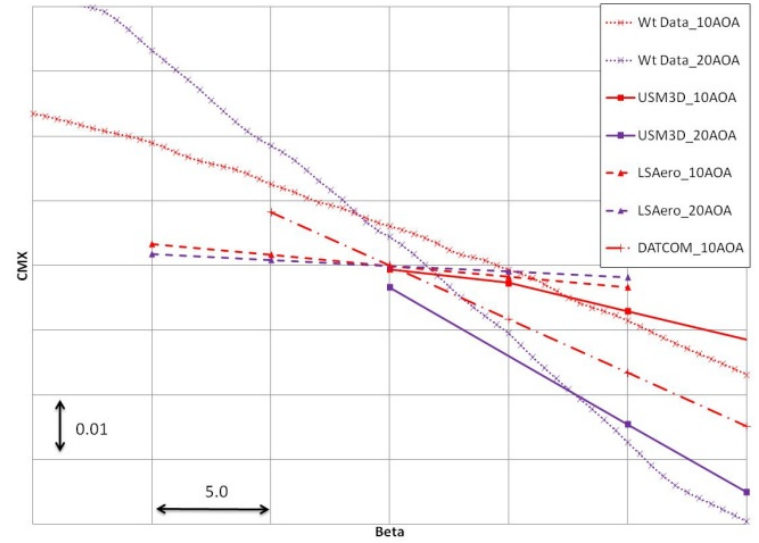

(b) $\mathrm{AOA}=10^{\circ}, \& 20^{\circ}$

Figure 11 Rolling Moment Coefficient vs Sideslip with Varying AOAs, Power-off.

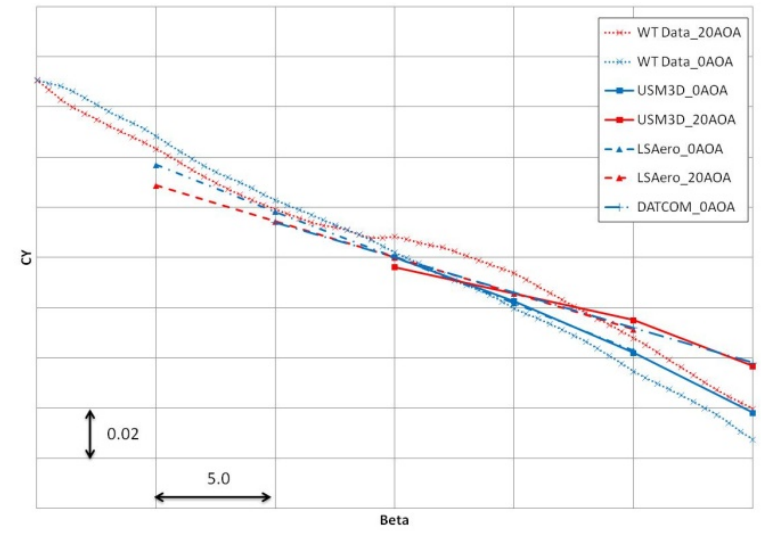

Figure 12 Side Force Coefficient vs Sideslip for $\mathrm{AOA}=0^{\circ} \& 20^{\circ}$, Power-off.

The power-off control surface effectiveness was evaluated by Kestrel, USM3D, LSAero, PMARC and Datcom. Test data was available for a horizontal tail deflection of $10.0^{\circ}$. The horizontal tail effectiveness can be found in Figure 13 for two horizontal tail deflections, a $-5^{\circ}$ trailing edge up deflection and a $10^{\circ}$ trailing edge down deflection. Calculations were also completed for $-12^{\circ}$ and $5^{\circ}$ deflections but are not plotted here. With increasing positive horizontal tail deflection, the lift coefficient and drag coefficient increased and the pitching moment coefficient became more negative. Kestrel and USM3D predicted very similar forces and moments for all horizontal tail deflections. The lift curve slopes were the same in the linear region with Kestrel, USM3D and LSAero. USM3D predicted a slightly higher stall angle of attack than Kestrel. PMARC predicted less lift when compared to the N-S solvers and Datcom predicted a steeper lift curve slope resulting in higher lift coefficients at higher angles of attack. The same trends between the test data and the computational analysis found in the baseline configuration can be seen for the horizontal tail effectiveness.

For the horizontal tail deflection cases, Kestrel and USM3D computed very similar drag coefficient trends [i.e., the increase in drag with increasing angle of attack (drag bucket)]. Datcom computes a higher drag coefficient in the linear region while LSAero computes a lower drag coefficient than the N-S solvers. Figure 13 shows that N-S solvers are required to accurately capture the entire drag coefficient bucket profile, which captures the higher drag associated with separation and stall.

The pitching moment coefficient agreed well between the N-S solvers and LSAero with a trailing edge up horizontal tail deflection. PMARC predicts a higher pitching moment coefficient but same trend. For the trailing edge down case, the N-S solvers compute a pitching moment coefficient that compares better with the experimental data but as angle of attack is increased, more discrepancy is seen between the CFD tools and the experimental data. The break in agreement occurs at the same angle of attack as a slight change in lift curve slope found in the linear region of the lift coefficient plots. The change in the pitching moment coefficient curve and the lift curve slope before the aircraft stalls could be a result of the flow stalling over the horizontal tail that would be predicted by the 
N-S solvers. The N-S solvers agree well with the test data at low angles of attack and better than the other methods at the higher angles of attack, and should be the method of choice for prediction of pitching moment coefficient especially with increasing horizontal tail deflections.
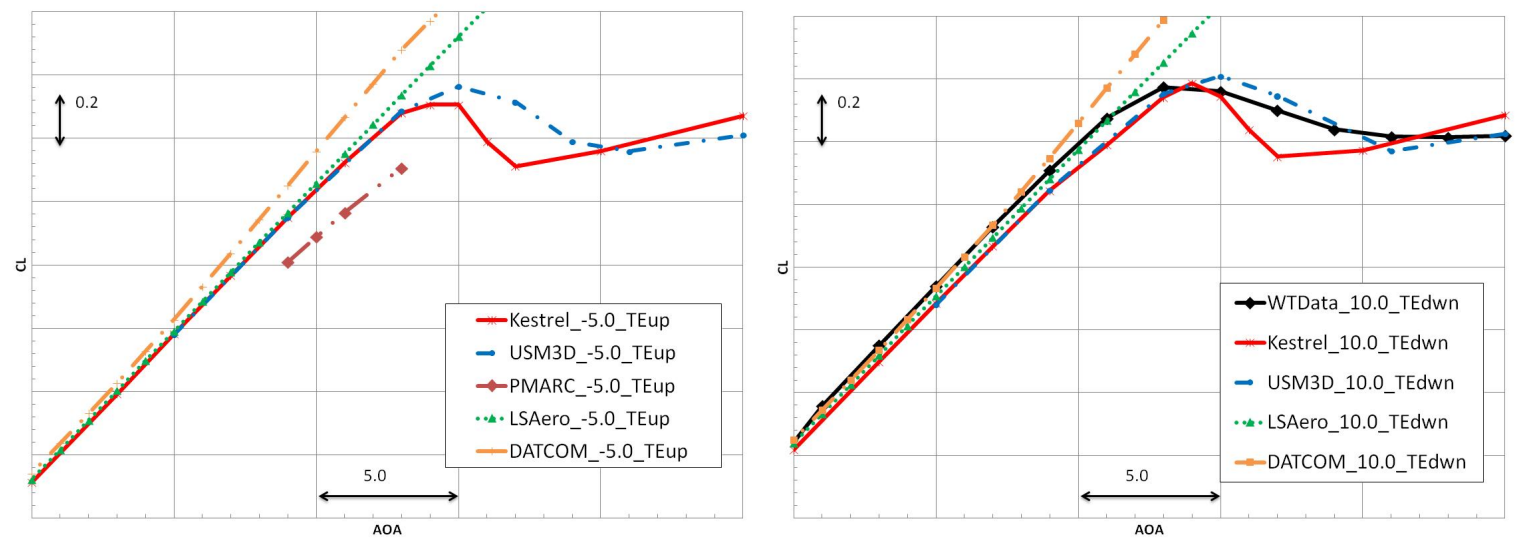

(a) Lift Coefficient vs AOA for Horizontal Tail Deflections of $-5.0^{\circ}$ and $10.0^{\circ}$
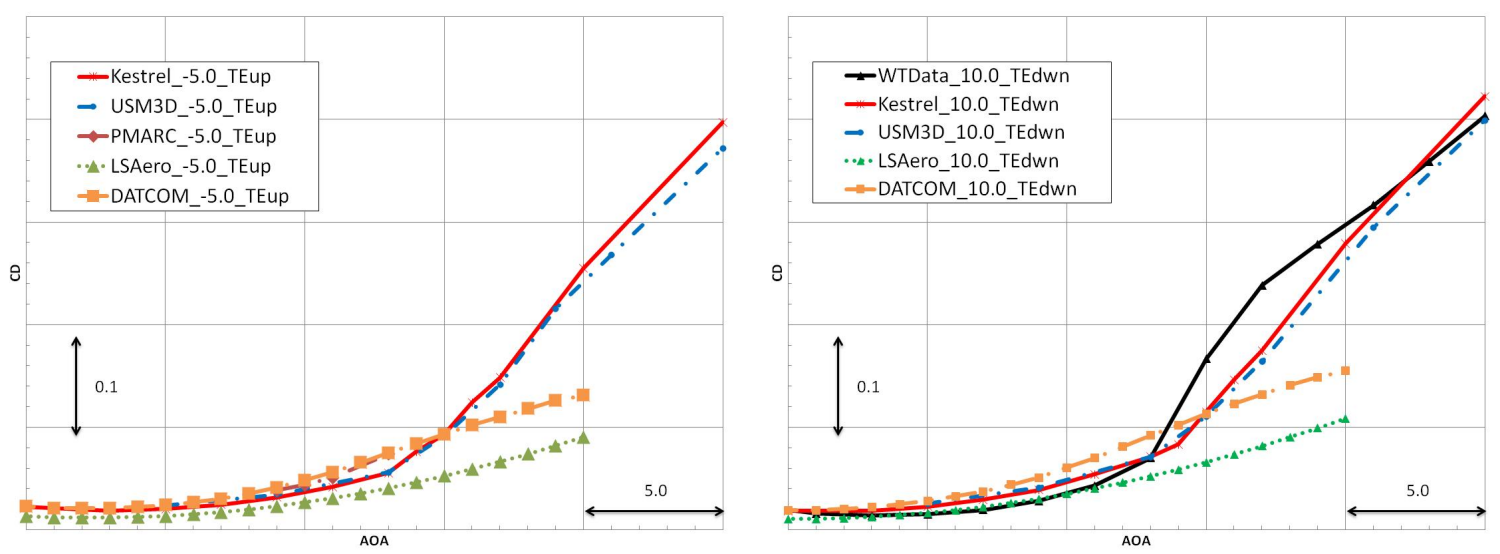

(b) Drag Coefficient vs AOA for Horizontal Tail Deflections of $-5.0^{\circ}$ and $10.0^{\circ}$
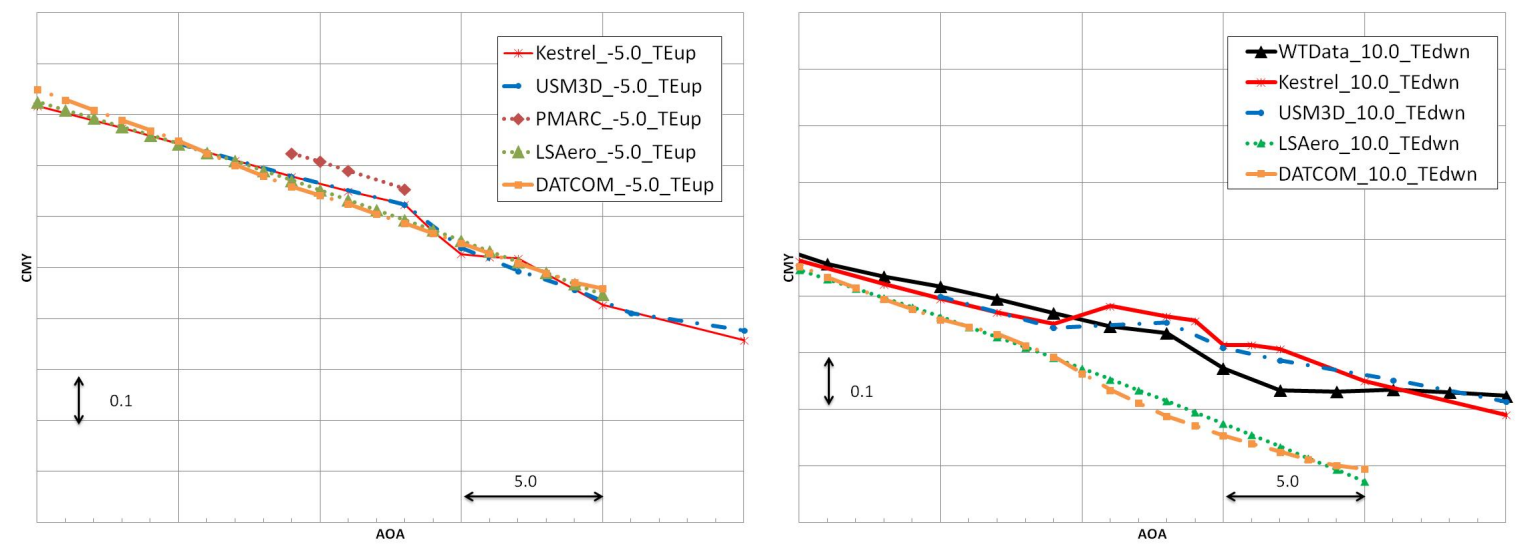

(c) Pitching Moment Coefficient vs AOA for Horizontal Tail Deflections of $-5.0^{\circ}$ and $10.0^{\circ}$ Figure 13 Kahu Horizontal Tail Effectiveness, Power-Off.

Computational tools can be used to determine the most accurate and efficient methods for modeling power effects of small UAVs. Initial computational work was focused on an isolated propeller. The Kahu blades were placed on a center body and the entire mesh was rotated about the $\mathrm{x}$-axis. The isolated propeller results were compared to the wind tunnel regression data (labeled "Parametric model") in Figure 14. The propeller power was 
computed from torque. Agreement with the wind tunnel thrust data was quite good considering uncertainties in the CAD construction procedure. The trend in thrust predicted by Kestrel mimicked that of the wind tunnel data. The power was under-predicted by the CFD tools.
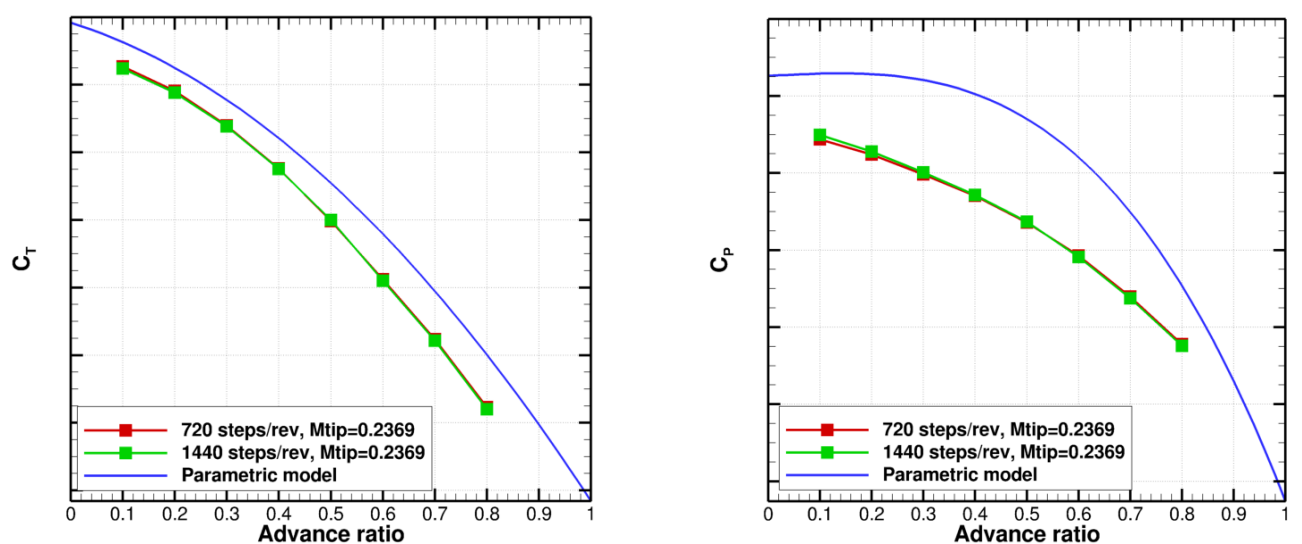

Figure 14 Thrust and Power Coefficients for Isolated Propeller Advance Ratio Sweep (Kestrel), Power-On

For a more realistic scenario, calculations with an overset spinning propeller were performed. The wing was removed from the CFD model to best represent the DSTO propulsion system test. The thrust produced can be found in Figure 15. The overset results match that of the isolated propeller regardless of variation in tip Mach number. To investigate differences in tip Mach number, a similar set of calculations should be done at a lower advance ratio where the difference due to changes in $\mathrm{M}_{\text {tip }}$ was more pronounced. While Kestrel captures the overall trend, it underpredicted thrust by a nearly constant amount relative to the WT regression data with $\mathrm{M}_{\text {tip }}=0.2369$. This may be a result of inaccuracies in CAD construction or erroneous assumptions about the angle at which the blades were mounted to the hub. Increasing blade pitch by $1^{\circ}$ might bring the results much closer to the wind tunnel data. Flow visualization was shown in Figure 16 with isosurfaces of Q-criterion, colored by vorticity magnitude. No premature dissipation of the propeller tip vortices was evident. The wake was convected smoothly to the tail. It only dissipates due to interaction with the tail and the end of the refined mesh just past the tail.

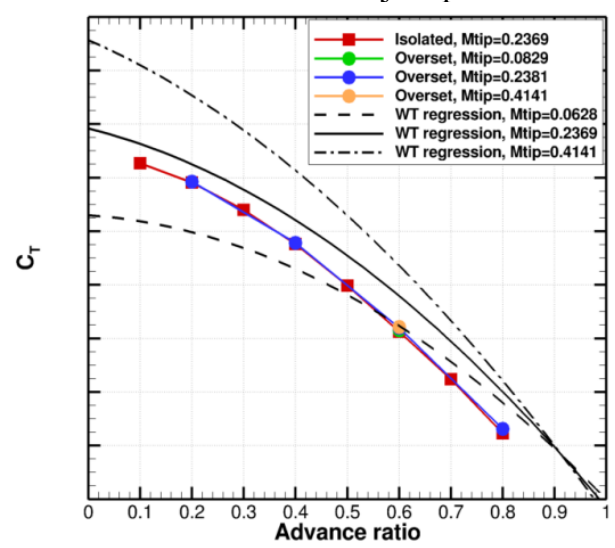

Figure 15 Thrust Coefficient for Overset Spinning Propeller Calculations (Kestrel), Power-On 


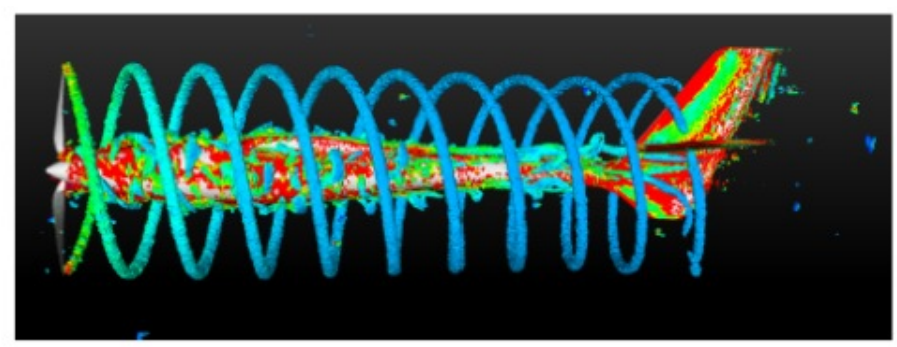

Figure 16 Iso-surfaces of Q-criterion, Colored by Vorticity Magnitude for the Overset Calculation, Power-On

Overset spinning propeller calculations are quite computationally expensive. To determine if there was a faster way to calculate basic propeller performance data, a simple model based on blade element and momentum theory (BEM) was created. Such a model runs in seconds on a single processor versus many hours on hundreds of processors. Once validated, a thrust curve from the BEM model could be used as input to an actuator disk method, which could be used to compute power effects on the aircraft. In this case the blade properties were derived from CAD. The airfoil lift and drag polar was generated using the XFOIL panel code at various Reynolds numbers. Figure 17 shows thrust coefficient from the BEM model compared against wind tunnel data and a Kestrel case with discrete blades. The BEM thrust correlates very well with the wind tunnel data at $\mathrm{M}_{\text {tip }}=0.2369$. Since tip Mach number does not appear in the BEM model equations, the thrust curves will not shift as tip Mach number increases or decreases.

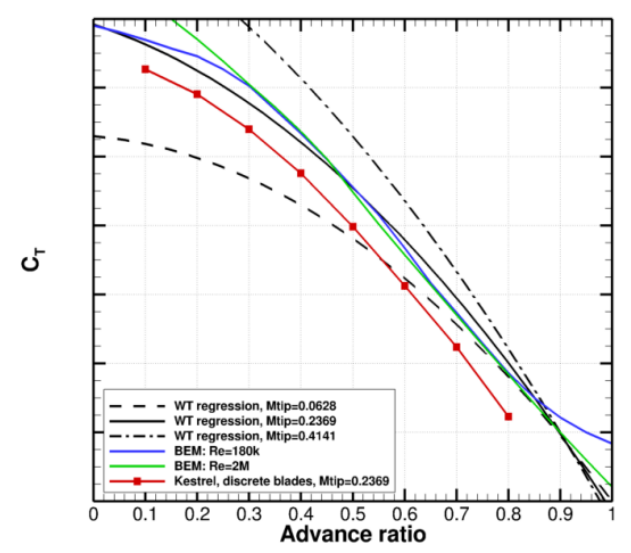

\section{Figure 17 Thrust Coefficient from the BEM Model Compared to Wind Tunnel Data and Overset Calculations (Kestrel), Power-On}

Since the propeller wake impinges on tail control surfaces, accurate predictions of power effects can be crucial in determining control effectiveness. Actuator disk methods provide an efficient means of including power effects in a CFD calculation, as compared to overset blades. Thrust and RPM were required as input for the actuator disk model. Thrust was taken from test data in this case but could also have been taken from the BEM model or another CFD calculation. Horizontal tail effectiveness at each flight condition was determined from the change in pitching moment due to the change in horizontal tail angle, $e_{\text {horizontal_tail }}=\Delta \mathrm{M}_{\mathrm{y}} / \Delta \delta_{\text {horizontal_tail }}$. Table 7 shows effectiveness and the percent difference between horizontal tail effectiveness with an actuator disk and without any power effects. It was apparent that power effects are much more pronounced at lower advance ratios. Figure 18 compares $|\mathrm{U}| / \mathrm{U}_{\infty}$ with an actuator disk at two advance ratios. There was a large wake at $J=0.1$ that bathes the entire tail, making the horizontal tail "see" an incoming velocity that was much higher than freestream. At $J=0.6$, the wake was barely visible, and the tail sees an incoming flow that is relatively undisturbed by the rotor. No comparisons with experimental data were possible since the wind tunnel data from the DSTO facility did not include forces and moments on the fuselage or tail. 
Table 7 Horizontal Tail Effectiveness Comparing Actuator Disk and Power-off Analyses (Kestrel)

\begin{tabular}{|l|c|c|c|}
\hline Rotor & Advance Ratio & Effectiveness (lb-in/deg) & \% difference \\
\hline Act. Disk & 0.1 & -1.4755 & 90 \\
\hline None & 0.1 & -0.1449 & \\
\hline Act. Disk & 0.6 & -5.4887 & 17 \\
\hline None & 0.6 & -4.5355 & \\
\hline
\end{tabular}
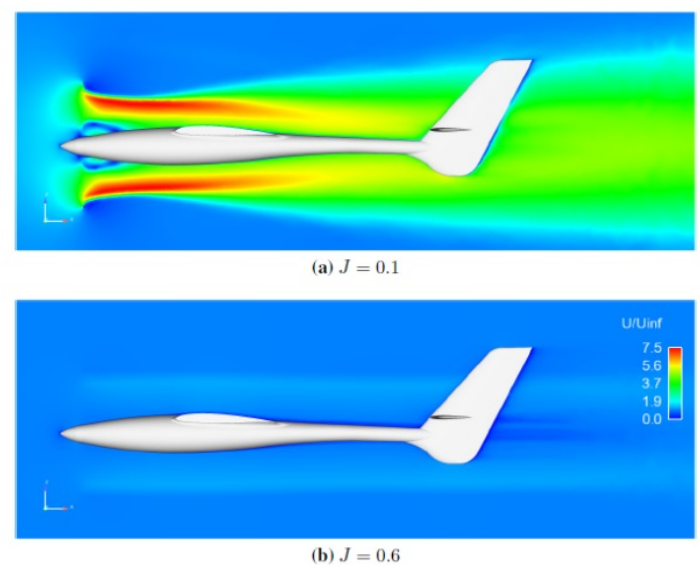

Figure $18|\mathbf{U}| \mathbf{U}_{\infty}$ Along Centerline of Actuator Disk Calculations, Power-On

\section{Conclusions}

Several computational methods were compared in their ability to predict aerodynamic forces and moments on a medium aspect ratio, small UAV, Kahu. The majority of tools were analyzed on the baseline configuration with no control surfaces deflected. The N-S computational tools had the best overall agreement with test data when run laminar for low angles of attack and turbulent for higher angles of attack. Datcom also compared well with the test data in the linear region, especially in lift but did not agree as well for rolling moment coefficient, drag coefficient, and side force coefficient. The low-order, potential flow solvers, especially LSAero, provided good predictions in the linear region for significantly cheaper cost both computationally and turn-around time. The N-S solvers required 4-8 hours to run per case while the potential flow solvers and Datcom took seconds to minutes to run. Both the N-S solvers and potential flow solvers required similar time for grid generation and input set-up. If rapid turn-around time and the production of a large amount of data are essential, potential flow methods offer a reasonable compromise between accuracy and turn-around time. If more time is available, a full N-S analysis is recommended to provide the user with more accurate data. Using a combination of N-S solvers and potential flow methods offers a great way to create a large aero database quickly. The low-order methods can be used in the linear region while the $\mathrm{N}-\mathrm{S}$ methods can be used for discrete points close to stall. For small UAVs, it is important to recognize if the flow over the wing is laminar or turbulent. These conclusions are valid for small vehicles at low speed with conventional geometry.

Power-effects are important to consider when analyzing small UAVs computationally. The most efficient method used in this paper for analyzing power effects was to use a BEM to obtain engine performance if not already known and then run computational analysis with an actuator disk instead of discrete blades. Analyzing a few runs with power-on can provide valuable information that can then be used to adjust the power-off database.

A wind tunnel test database was also created in support of this project. The test database provides a comparative dataset for all computational work performed for Kahu. The baseline, powered-off results and a few horizontal tail deflections have been presented in this paper. All other results, including the DOE matrix design and data (power and control deflection effects), will be presented in the future.

Relative to the work presented, further CFD analyses are recommended that include modeling the tunnel walls and sting to determine if better agreement can be achieved between CFD and experimental data. Also, it would be desirable to do this work in a low speed facility where the installation effects aren't as large and one that has more of a performance heritage. 


\section{Acknowledgments}

The authors would like to thank the TTCP program and all personnel who have contributed and participated in this effort. The authors would like to acknowledge the NZ DTA, as this work would not have been possible without the Kahu vehicle and the invaluable correspondence they provided. The authors would like to thank all agencies that supported this work, NAVAIR, AFRL, NASA Langley, DTA and DSTO. The authors would like to thank those that contributed to this work from DSTO, especially Geoff Brian and Mike Grant for all their input, and support.

The authors would also like to thank the many NASA Langley individuals involved with the wind tunnel model design, construction, functional design, and wind tunnel testing; especially Mike Logan, Mark Cagle, Sue Grafton, Wes O'Neal, Steve Bauer, Gene Adams, Dan Vicroy, Steve Riddick, Gautam Shah, and Mark Croom, along with the other team folks in the fabrication area and Flight Dynamics Branch. In addition, the authors would like to thank the Environmentally Responsible Aviation Project and the NASA Engineering \& Safety Center's Aerosciences discipline team at NASA Langley for funding the wind tunnel model and wind tunnel test in support of this TTCP effort.

\section{References}

${ }^{1}$ Morton, S. A., McDaniel, D. R., Sears, D. R., Tillman, B., and Tuckey, T. R., “ Kestrel: A Fixed Wing Virtual Aircraft Product of the CREATE Program," AIAA-2009-0338, January 2009.

${ }^{2}$ Morton, S. A., McDaniel, D. R., Sears, D. R., Tillman, B., and Tuckey, T. R., "Kestrel User's Guide: v2.0,” 2012, Eglin, FL.

${ }^{3}$ Cobalt Solutions, LLC. "Cobalt Version 4 Users Manual," 2007. Springfield, OH.

${ }^{4}$ Frink, N. T., Pirzadeh, S., Parikh, P., Pandya, M. J., and Bhat, M. K., "The NASA Tetrahedral Unstructured Software System (TetrUSS),” The Aeronautical Journal, Vol. 104, No. 1040, Oct. 2000, pp. 491-499.

${ }^{5}$ Spalart, P. R., and Allmaras, S. R., "A One-Equation Turbulence Model for Aerodynamic Flows," AIAA Paper 97-0644, Jan. 1997.

${ }^{6}$ Ashby, D.L., "PMARC - Panel Method Ames Research Center Guide," Report ARC-12642, 1994, Ames CA

${ }^{7}$ Deperrois, A. "XFLR5, About Stability Analysis Using XFLR5," 2010

${ }^{8}$ Katz, J.A., and Plotkin, A., Low Speed Aerodynamics, 2nd ed., Cambridge University Press, Cambridge, UK, 2001.

${ }^{9}$ Drela, M., and Giles, M.B., "Viscous-Inviscid Analysis of Transonic and Low Reynolds Number Airfoils," AIAA Journal, Vol. 25, No. 10, 1987, pp. 1347-1355.

${ }^{10}$ McDonnel Douglas Astronautics Company, "The USAF Stability and Control Datcom User's Manual," AFFDL-TR-793032, 1999, St. Louis, Missouri

${ }^{11}$ Malinda Goodrich and Jenele Gorham, The Library of Congress - Wind Tunnels of the Western Hemisphere; June 2008; pp 55-56.

${ }^{12}$ Bedwell, K., Dansie, J., Brian, G., "Characterising the Kahu Hawk UAV Propulsion Systems Performance,” DSTO-TN1184, Defence Science and Technology Organisation, June 2013.

Surface Modeling, Grid Generation, and Related Issues in CFD Solutions, NASA CP-3291, 9-11 May, 1995.

${ }^{13}$ Samareh, J. A., "GridTool: A Surface Modeling and Grid Generation Tool," Proceedings of the Workshop on Surface Modeling, Grid Generation, and Related Issues in CFD Solutions, NASA CP-3291, 9-11 May, 1995.

${ }^{14}$ Lohner, R. and Parikh, P., "Three-dimensional grid generation by the advancing front method," International Journal for Numerical Methods in Fluids," Vol. 8, Issue 10, 1988, pp. 1135-1149.

${ }^{15}$ Pirzadeh, S. Z., "Three-dimensional unstructured viscous grids by the advancing layer method," AIAA Journal, Vol. 33 , No. 1, 1996, pp. 43-49.

${ }^{16}$ Pirzadeh, S. Z., “Advanced unstructured grid generation for complex aerodynamic applications,” AIAA Journal, Vol. 48, No. 5, 2010, pp. 904-915.

${ }^{17}$ Geuzaine, Christophe and Remacle, Jean-François, "Gmsh is a three-dimensional finite element mesh generator with builtin pre- and post-processing facilities Version 2.5," 2010

${ }^{18}$ Barlow, J. B., Rae, W. H. Jr., and Pope, A., Low-Speed Wind Tunnel Testing, Third Edition, John Wiley \& Sons, Inc., New York, 1999. 